\title{
Ultrasensitive Detection of Glyphosate Using CdTe Quantum Dots in Sol-Gel-Derived Silica Spheres Coated with Calix[6]arene as Fluorescent Probes
}

\author{
Tao Li, Yunyou Zhou*, Junyong Sun, Kai Wu \\ Anhui Key Laboratory of Functional Molecular Soilds, Anhui Key Laboratory of Chemo/Biosensing, \\ College of Chemistry and Materials Science, Anhui Normal University, Wuhu, China \\ Email: *zy161299@mail.ahnu.edu.cn
}

Received September 17, 2011; revised November 1, 2011; accepted November 15, 2011

\begin{abstract}
We have developed a simple method for the preparation of highly fluorescent and stable, water-soluble CdTe quantum dots in sol-gel-derived composite silica spheres which were coated with calix[6]arene. The resulting nanoparticles (NPs) were characterized in terms of UV, fluorescence and FT-IR spectroscopy and TEM. The results show that the new NPs display more intense fluorescence intensity and are more stable than its precursors of the type $\mathrm{SiO}_{2} / \mathrm{CdTe}$. Under the optimum, the novel NPs exhibit a higher selectivity and ultrasensitive fluorescence probes for the determination of glyphosate over other pesticides, the fluorescence intensity increase with the concentration of glyphosate in the range from 1.0 to $25.0 \mathrm{nmol} / \mathrm{L}$ and the detection limit is low to $0.0725 \mathrm{nmol} / \mathrm{L}$. A mechanism is suggested to explain the inclusion process by a Langmuir binding isotherm.
\end{abstract}

Keywords: Quantum Dots; $\mathrm{SiO}_{2} / \mathrm{CdTe} \mathrm{NPs} ; \mathrm{C}[6] / \mathrm{SiO}_{2} / \mathrm{CdTe} \mathrm{NPs}$; Glyphosate; Fluorescence Probes

\section{Introduction}

Glyphosate ([N-(phosponomethyl)glycine]), one of the mostly important organophosphorous (OP) pesticides [1], is a broad-spectrum, nonselective herbicide to effectively control weeds and vegetation [2]. It is widely used in lawns, gardens and along sidewalks for urban landscapes. In recent years, glyphosate has been attracted increasing attention because of its pollution to the aquatic environment and its potential adverse effects of these compounds to ecosystems and human [3]. Common methodologies used for glyphosate detection are mainly based on chromatographic methods [4,5] and electrochemical methods [6,7], which suffer from high cost and low sensitivity problems. Thus, it is very necessary to develop a simple and convenient method for the efficient detection of glyphosate.

Water-soluble semiconductor nanoparticles (quantum dots, QDs) have generated great fundamental and technical interests due to their superior optical and electronic properties [8], and have been widely used as fluorescence probes in biology and medicine [9]. Recently, the functionalization of QDs surfaces using macro-cyclic host molecules with specific ligands, has attracted considerable attention because of its potential applications for fabrication of sophisticated sensors [10]. For example, as

*Corresponding author. the third generation of host molecules, calixarene and their derivatives have been used as capping ligands for QDs due to their unique advantages in the construction of molecules recognition systems, giving rise to watersoluble QDs for their applications [11]. In previous studies, the calixarene formed a bilayer structure with TOPO (Trioctylphosphine Oxide) molecules surrounding QDs by hydrophobic interaction [12-14]. However, TOPO layer of QDs is unstable in dynamic equilibrium with the surrounding medium, which is a significant obstacle for the applications. Therefore, it is necessary to improve the stability of surface modification of QDs in solutions. We have found that encapsulation of the nanoparticles with silica shell is advantageous for applications such as bio-labeling, because the inert silica shell can keep the nanoparticles out of oxidation. Furthermore, silica particles can be increased in size by "seeded" growth and assembled to bigger aggregates such as photonic crystals [15]. Additionally, silica is chemically inert and optically transparent. Therefore, QDs coated with inert materials may improve the chemical and photochemical stabilities, especially in aqueous systems [16]. Based on the above research results, we can develop novel fluorescence probes, which have synergetic superior properties from both QDs and calixarene.

Herein, we report the synthesis of CdTe nanocrystals 
in sol-gel-derived composite silica spheres which were then coated with calix[6]arene $\left(\mathrm{C}[6] / \mathrm{SiO}_{2} / \mathrm{CdTe} \mathrm{NPs}\right.$, Scheme 1), the $\mathrm{SiO}_{2} / \mathrm{CdTe}$ NPs and $\mathrm{C}[6] / \mathrm{SiO}_{2} / \mathrm{CdTe}$ NPs were characterized in terms of $\mathrm{UV}$, fluorescence and FT-IR spectroscopy and TEM (the synthesis and characterization of $\mathrm{SiO}_{2} / \mathrm{CdTe} \mathrm{NPs}$ and $\mathrm{C}[6] / \mathrm{SiO}_{2} / \mathrm{CdTe} \mathrm{NPs}$, as can be seen from the myself literature [17]). Moreover, we also demonstrated the potential application of asprepared QDs as fluorescence probes for simple, rapid, ultrasensitive, and highly selective determinations of glyphosate. Comparing with other electrochemical and chromatographic methods, the present method is simple, fasts, lower cost and possess low detection limit for the determination of glyphosate. This study may also extend the potential application range of $\mathrm{C}[6] / \mathrm{SiO}_{2} / \mathrm{CdTe} \mathrm{NPs}$ in environmental chemistry.

\section{Experimental}

\subsection{Instrumentation}

Fluorescence spectra and relative fluorescence intensities were measured on a Hitachi F-4500 spectrofluorometer (Tokyo, Japan) with a xenon lamp, $1.0 \times 1.0 \mathrm{~cm}^{2}$ quartz cell. Excitation and emission bandwidths were set to 5.0 $\mathrm{nm}$ and $5.0 \mathrm{~nm}$, respectively. All measurements were carried out at desired temperature using a thermostatic cell holder. A model pHS-3C (Dazhong Analytical Instruments Factory, Shanghai, China) $\mathrm{pH}$ meter was used for accurate adjustment of $\mathrm{pH}$.

\subsection{Reagents}

All reagents used were of analytical-reagent grade or the best grade commercially. Doubly deionized water was used throughout. Pesticide standards (glyphosate, chlorpyrifos, carbaryl, cyromazine, imidacloprid, methiocarb) were obtained from Aladdin-reagent, China. All pesticide standards were up to 99\% purity. Chlorpyrifos and methiocarb were dissolved in the mixture of water and ethanol, and others were dissolved in water and stored at room temperature.

\subsection{Determination of Pesticides}

The selectivity of the $\mathrm{SiO}_{2} / \mathrm{CdTe}$ NPs and $\mathrm{C}[6] / \mathrm{SiO}_{2} /$ CdTe NPs as fluorescence probes for glyphosate is evaluated by testing the response of assay to other environment relevant various pesticides. Figure 1 shows the effect of $1 \times 10^{-5} \mathrm{~mol} / \mathrm{L}$ relevant pesticides on the fluorescence of $\mathrm{SiO}_{2} / \mathrm{CdTe} \mathrm{NPs}$ and $\mathrm{C}[6] / \mathrm{SiO}_{2} / \mathrm{CdTe} \mathrm{NPs}$, including glyphosate, chlorpyrifos, carbaryl, cyromazine, imidacloprid, methiocarb, which are shown in Figure 2. Only glyphosate has a selective effect on the fluorescence of $\mathrm{C}[6] / \mathrm{SiO}_{2} / \mathrm{CdTe} \mathrm{NPs}$ over turns out to be increased sensitively in the presence of glyphosate in water. Yet for $\mathrm{SiO}_{2} / \mathrm{CdTe}$ NPs, all pesticides have very little effects. It is rational that $\mathrm{C}[6]$ plays an important role in selective fluorescence response to glyphosate. It is known that the well-defined structure of the calixarene cavities can be exploited for the inclusion of organic guest. However, the cavity of $C[6]$ is not sufficiently large enough to accommodate bulk aromatic pesticides excluding a small linear molecule like glyphosate, which results in the selective fluorescence response to glyphosate.

\section{Results and Discussion}

\subsection{Effect of pH Fluorescence Intensity of $\mathrm{C}[6] / \mathrm{SiO}_{2} / \mathrm{CdTe} \mathrm{NPs}$}

The $\mathrm{pH}$ of the solution has a great effect on the fluorescence intensity of the $\mathrm{C}[6] / \mathrm{SiO}_{2} / \mathrm{CdTe} \mathrm{NPs}$. The $\mathrm{pH}$ effect is investigated in a range between 4.0 and 11.0. It is found that the fluorescence intensity is decreased quickly in acidic, meanwhile, in also decreased gradually in strong

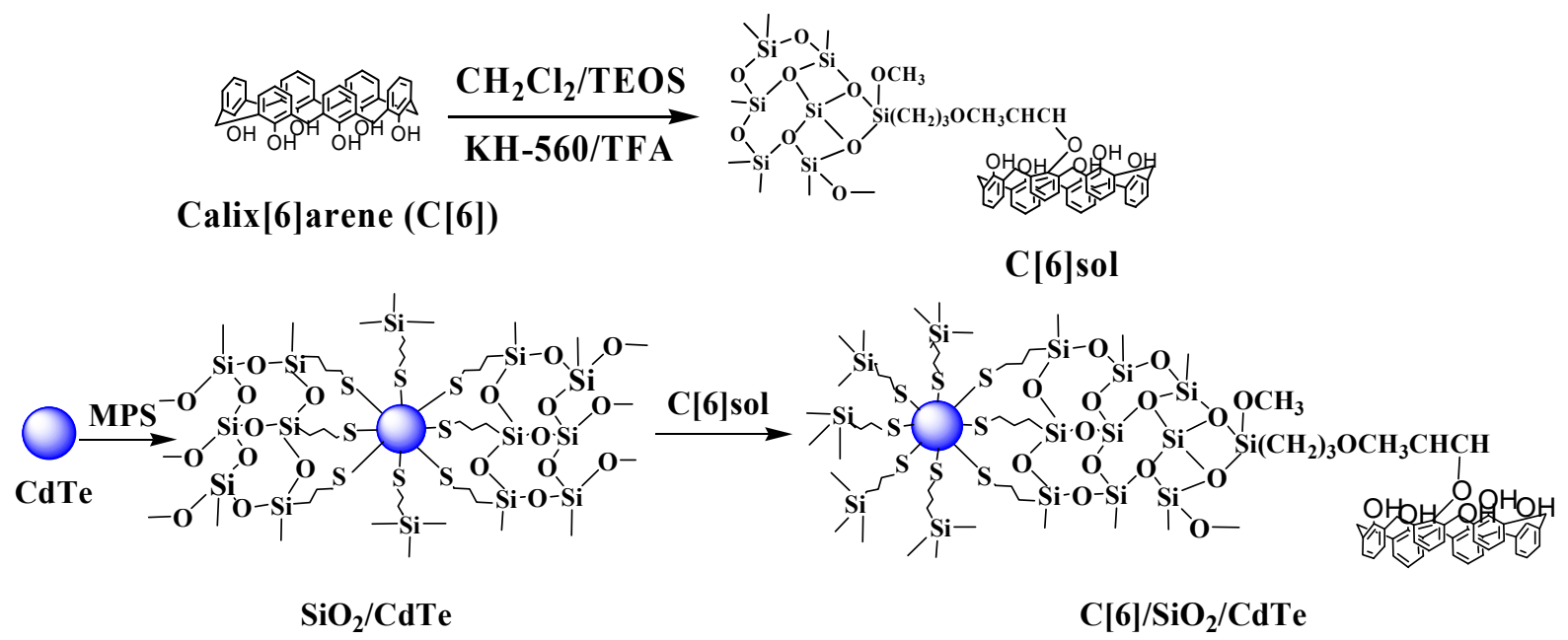

Scheme 1. Formation of $\mathrm{C}[6] / \mathrm{SiO}_{2} / \mathrm{CdTe} \mathrm{NPs}$. 


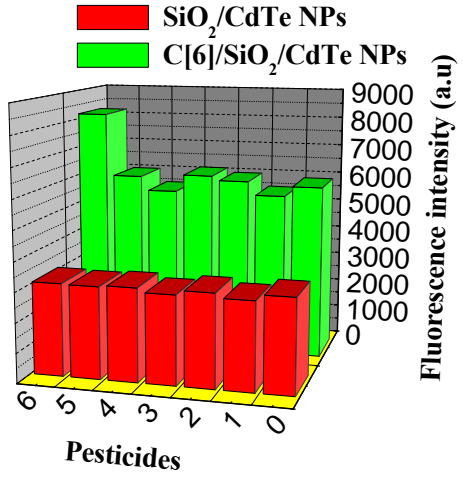

Figure 1. Effect of $1 \times 10^{-5} \mathrm{~mol} / \mathrm{L}$ relevant pesticides on the fluorescence of $\mathrm{SiO}_{2} / \mathrm{CdTe} \mathrm{NPs}$ and $\mathrm{C}[6] / \mathrm{SiO}_{2} / \mathrm{CdTe} \mathrm{NPs}$ (from 0 to 6: control, chlorpyrifos, cyromazine, carbaryl, imidacloprid, methiocarb, and glyphosate).<smiles>O=C(O)CNCP(=O)(O)O</smiles><smiles>O=[N+]([O-])C1=NCCN1Cc1ccc(Cl)nc1</smiles>
imidacloprid<smiles>CC(=O)Oc1cccc2ccccc12</smiles>
carbaryl<smiles>Nc1nc(N)nc(NC2CC2)n1</smiles><smiles>CCOP(=O)(OCC)Oc1nc(Cl)c(Cl)cc1Cl</smiles>
chlorpyrifos<smiles>CNC(=O)Oc1cc(C)c(C)c(C)c1</smiles>

Figure 2. The chemical structure of pesticides investigated.

basic media, as shown in Figure 3. At low pH, the surface of $\mathrm{C}[6] / \mathrm{SiO}_{2} / \mathrm{CdTe}$ NPs may be dissolved, resulting in surface defects. In a $\mathrm{pH}$ medium up to 4.0, the fluorescence emission has been completely quenched. However, at high $\mathrm{pH}, \mathrm{OH}^{-}$could nucleophilicly attack the surface to cleave calixarene and create surface defects. Therefore, we select $\mathrm{pH}=9.0$ for further study.

\subsection{Effect of the $\mathrm{C}[6] / \mathrm{SiO}_{2} / \mathrm{CdTe} \mathrm{NPs}$ Concentration}

In the experiment, $\mathrm{C}[6] / \mathrm{SiO}_{2} / \mathrm{CdTe} \mathrm{NPs}$ are fluorescence reagent and its concentration can effect the response to glyphosate. When $\mathrm{C}[6] / \mathrm{SiO}_{2} / \mathrm{CdTe}$ NPs concentration is

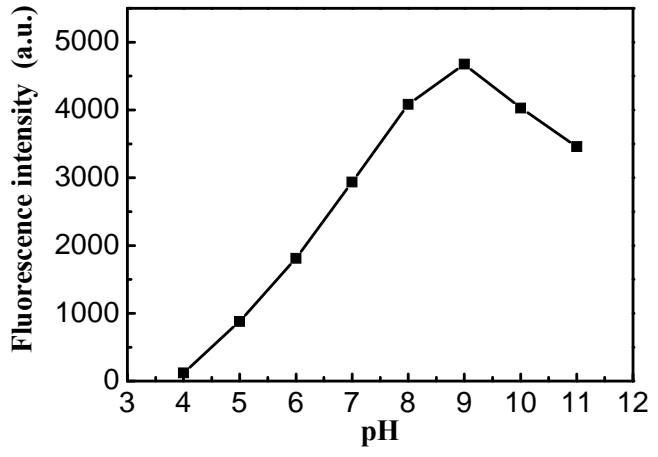

Figure 3. Effect of pH fluorescence intensity of $\mathrm{C}[6] / \mathrm{SiO}_{2} /$ CdTe NPs, 293 K.

too low, the fluorescence intensity increased with increasing glyphosate concentration, but the fluorescence intensity of the host system is weak and the linear range is narrow; when $\mathrm{C}[6] / \mathrm{SiO}_{2} / \mathrm{CdTe} \mathrm{NPs}$ concentration is too high, the blank signal is too high and the increase effects by low concentration of glyphosate decreased. Considering these factors, $6.0 \times 10^{-7} \mathrm{~mol} / \mathrm{L} \mathrm{C}[6] / \mathrm{SiO}_{2} /$ CdTe NPs is recommended in our experiments (see Figure 4).

\subsection{Calibration Curve and Detection Limit}

According to the proposed method a calibration curve is constructed under the optimal conditions. Figure 5 describes the glyphosate concentration $(C)$ dependence of the fluorescence intensity of the $\mathrm{C}[6] / \mathrm{SiO}_{2} / \mathrm{CdTe} \mathrm{NPs}(F)$. It can see that the emission intensity of $\mathrm{C}[6] / \mathrm{SiO}_{2} / \mathrm{CdTe}$ NPs increases sharply in response to glyphosate. The linear range is obtained from 1.0 to $25.0 \mathrm{nmol} / \mathrm{L}$. The linear regression equation is as follows: $F=480.605+$ $21.186 C(\mathrm{nmol} / \mathrm{L})$, with a correlation coefficient of 0.99947 $(n=13)$, the detection limit (LOD), calculated following the $3 \sigma$ IUPAC criteria, is low to $0.0725 \mathrm{nmol} / \mathrm{L}$ and the relative standard deviation is $0.1048 \%$ (eleven replicate measurements of a solution). For comparative purpose, the analytical performance of several selected methods for glyphosate detection is summarized in Table 1. In comparison with previous results, the proposed method possesses comparable or superior detection limit and linear range, as shown in Table 1.

\subsection{Discussion of Interaction Mechanism}

The glyphosate concentration dependence of the fluorescence intensity of $\mathrm{C}[6] / \mathrm{SiO}_{2} / \mathrm{CdTe}$ NPs shown in Figure 6. Curve A shows that the emission intensity of $C[6] /$ $\mathrm{SiO}_{2} / \mathrm{CdTe}$ NPs increases sharply in response to glyphosate at a concentration of $0-600 \mathrm{nmol} / \mathrm{L}$. However, if the concentration of glyphosate reaches $100 \mathrm{nmol} / \mathrm{L}$, the fluorescence intensity is decreased. The concentration dependence of fluorescence intensity follows the binding 
Table 1. Comparison of the linear range and detection limit of different methods for determination of glyphosate.

\begin{tabular}{|c|c|c|c|c|}
\hline Method & Reagent/sample & Linear range (mol/L) & Detection limit (mol/L) & Reference \\
\hline GC/EI/MS/MS & AMPA & $(0.029-2.96) \times 10^{-8}$ & $1.48 \times 10^{-10}$ & [18] \\
\hline HPLC/EC & Water & $(0.59-106.5) \times 10^{-5}$ & $2.3 \times 10^{-6}$ & [7] \\
\hline HILIC & Copper ( II ) complex & $(0.059-20.1) \times 10^{-5}$ & $5.9 \times 10^{-7}$ & [19] \\
\hline IC/ICP/MS & Soil extracts & $(0.059-59.1) \times 10^{-7}$ & $8.87 \times 10^{-9}$ & [20] \\
\hline EC & NiAl-LDH modified electrodes & $(0.01-0.9) \times 10^{-3}$ & $1.0 \times 10^{-6}$ & {$[21]$} \\
\hline CE & Pool water & $(0.118-296) \times 10^{-5}$ & $1.18 \times 10^{-6}$ & {$[22]$} \\
\hline HPLC/ELC & Tris (2,2’-bipyridyl)ruthenium ( II ) & - & $1.0 \times 10^{-8}$ & [6] \\
\hline HPLC & Soil & $(5.92-59.2) \times 10^{-5}$ & $2.36 \times 10^{-7}$ & [23] \\
\hline Suppressed conductance & Drinking water & $(0-1.18) \times 10^{-5}$ & $2.96 \times 10^{-7}$ & {$[24]$} \\
\hline Fluorescence & N-Nitroso Derivative & $(1.78-3.55) \times 10^{-4}$ & $2.96 \times 10^{-5}$ & {$[25]$} \\
\hline Spectrophotometry & $\mathrm{C}[6] / \mathrm{SiO}_{2} / \mathrm{CdTe}$ nanparticles & $(1.0-25.0) \times 10^{-9}$ & $7.25 \times 10^{-11}$ & This work \\
\hline
\end{tabular}

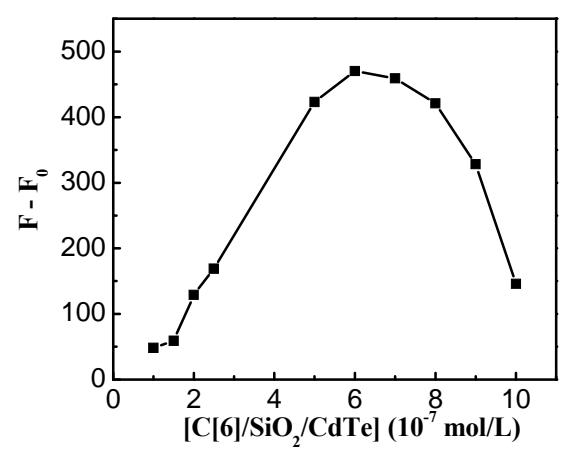

Figure 4. Effect of the concentration of $\mathrm{C}[6] / \mathrm{SiO}_{2} / \mathrm{CdTe} \mathrm{NPs}$ on the relative fluorescence intensity $\left(F_{0}-F\right)$ of system, where $F$ and $F_{0}$ are the fluorescence intensity of the $C[6] /$ $\mathrm{SiO}_{2} / \mathrm{CdTe}$ NPs at given glyphosate concentration and in a glyphosate free solution. $C_{\text {glyphosate }}=1.0 \times 10^{-8} \mathrm{~mol} / \mathrm{L}, \mathrm{pH}=$ 9.0, $293 \mathrm{~K}$.

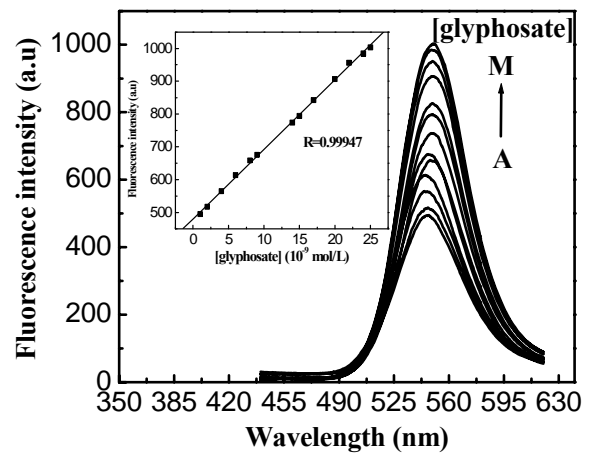

Figure 5. Fluorescence emission spectra of the $\mathrm{C}[6] / \mathrm{SiO}_{2} /$ CdTe NPs showing changes due to increasing concentration of glyphosate (A - M: 1.00, 2.00, 4.00, 6.00, 8.00, 9.00, 14.00, 15.00, 17.0, 20.00, 22.00, 24.00, $\left.25.00 \times 10^{-9} \mathrm{~mol} / \mathrm{L}\right)$. The emission intensity of $\mathrm{C}[6] / \mathrm{SiO}_{2} / \mathrm{CdTe} \mathrm{NPs}$ increase sharply in response to glyphosate, the linear range is obtained from 1.00 to $25.00 \mathrm{nmol} / \mathrm{L}$.

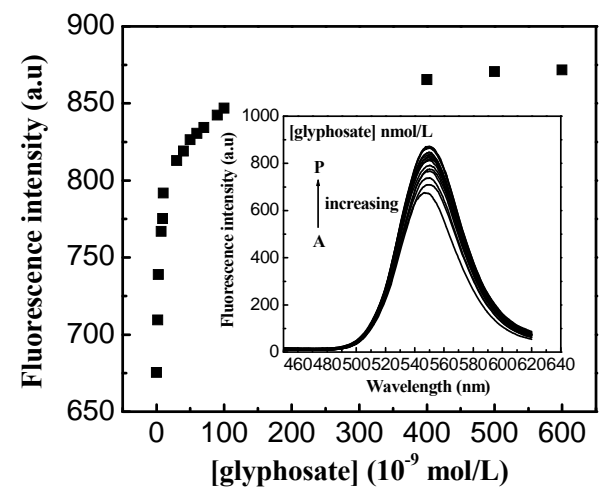

Figure 6. Curve shows that the emission intensity of $\mathrm{C}[6] /$ $\mathrm{SiO}_{2} / \mathrm{CdTe} \mathrm{NPs}$ increases sharply in response to glyphosate at a concentration of $0-600 \mathrm{nmol} / \mathrm{L}$. However, if the concentration of glyphosate reaches $100 \mathrm{nmol} / \mathrm{L}$, the fluorescence intensity is decreased.

of glyphosate to the cavity of the C[6] on the surface of $\mathrm{C}[6] / \mathrm{SiO}_{2} / \mathrm{CdTe} \mathrm{NPs}$ and is effectively described by a Langmuir-type binding isotherm [26]. The fluorescence intensity is increased with increasing glyphosate concentration. According to the Langmuir equation, the surface of the $\mathrm{C}[6] / \mathrm{SiO}_{2} / \mathrm{CdTe}$ NPs consists of a finite number of binding sites. Each of the binding sites can absorb one pesticide from the solution.

The fraction of occupied sites is defined as $\theta$. The rate of binding of pesticides to the surface is proportional to the pesticide concentration $C$ in the analytic solution and to the fraction of available binding sites $1-\theta$. The rate of binding $R_{b}$, of pesticide to the surface is expressed as

$$
R_{b}=K_{b} C(1-\theta)
$$

The rate of desorption of bound pesticide from the sur- 
face depends only on the fraction of occupied binding sites and can be express as

$$
R_{b}=K_{b} \theta
$$

The rate of binding is equal to the rate of desorption at equilibrium

$$
K_{d} \theta=K_{b} C(1-\theta)
$$

The equation can be solved for $\theta$ as a function of the ratio $B=K_{b} / K_{d}$.

$$
\theta=(B C) /(1+B C)
$$

The fraction of occupied binding sites $\theta$, is related to the ratio between the signal obtained at given pesticide concentration $(I)$ and the maximum intensity $\left(I_{\max }\right)$.

$$
\theta=I / I_{\max }
$$

Therefore, an expression that related the pesticide concentration $C$, to the signal intensity can be written as

$$
I / I_{\max }=\left(1 / B I_{\max }\right)+\left(1 / I_{\max }\right) C
$$

This equation can be linearized to take the form

$$
C / I=\left(1 / B I_{\max }\right)+\left(1 / I_{\max }\right) C
$$

Accordingly, if the Langmuir description of the binding of glyphosate on the surface of the $\mathrm{C}[6] / \mathrm{SiO}_{2} / \mathrm{CdTe}$ NPs is correct, a plot of $C / I$ as a function of $C$ should be linear. The dependence of $C / I$ as a function of $C$, where $C$ is the glyphosate concentration and $I$ is the fluorescence intensity of the $\mathrm{C}[6] / \mathrm{SiO}_{2} / \mathrm{CdTe} \mathrm{NPs}$ at given glyphosate concentrations, is shown in Figure 7. A relative linearity is observed throughout the entire range of glyphosate concentration. The binding constant $B$ is found to be 0.069 , and the coefficient of the linear fit is 0.99958 . The remarkable Langmuir fit suggests that the probability of binding more than one glyphosate to the surface of an individual $\mathrm{C}[6] / \mathrm{SiO}_{2} / \mathrm{CdTe} \mathrm{NPs}$, which is imperative for aggregation or non-Langmuir binding isotherm due to island formation, is negligible under the experiment conditions.

The observed fluorescence emission enhancement at the concentration $0-600 \mathrm{nmol} / \mathrm{L}$ of glyphosate may be correlated to the structural changes of the calixarenegroup shell surrounding the NPs core upon intercalation, which may result from the generation of new and efficient radiative path involving the bound glyphosate and /or from the suppression of a nonradiative process. When adding glyphosate to the $\mathrm{C}[6] / \mathrm{SiO}_{2} / \mathrm{CdTe} \mathrm{NPs}$, the glyphosate intercalation restricts the calixarene-cavity distort, which induces a uniform arrangement. Such ordered orientation and/or enhanced conformational rigidity of the surface substituents may suppress the quenching path to the medium by effective core protection and thus increase the fluorescence intensity [27]. A similar mechanism may be involved in the present case with respect to

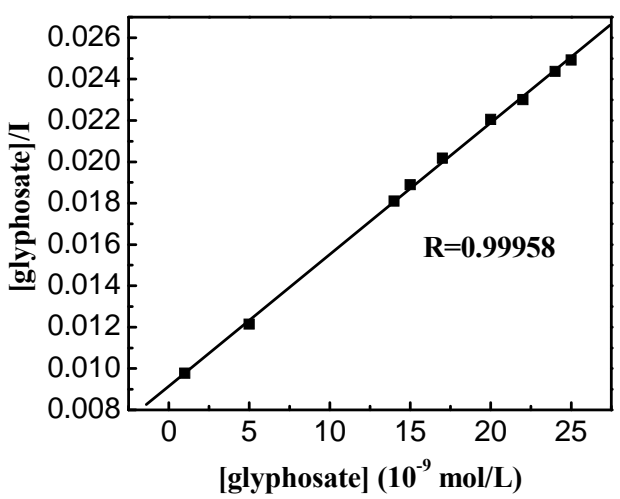

Figure 7. Langmuir binding isotherm description of the data showing a linear fit throughout the glyphosate concentration range, the binding constant $B$ is found to be 0.069 and the coefficient of the linear fit is $\mathbf{0 . 9 9 9 5 8}$.

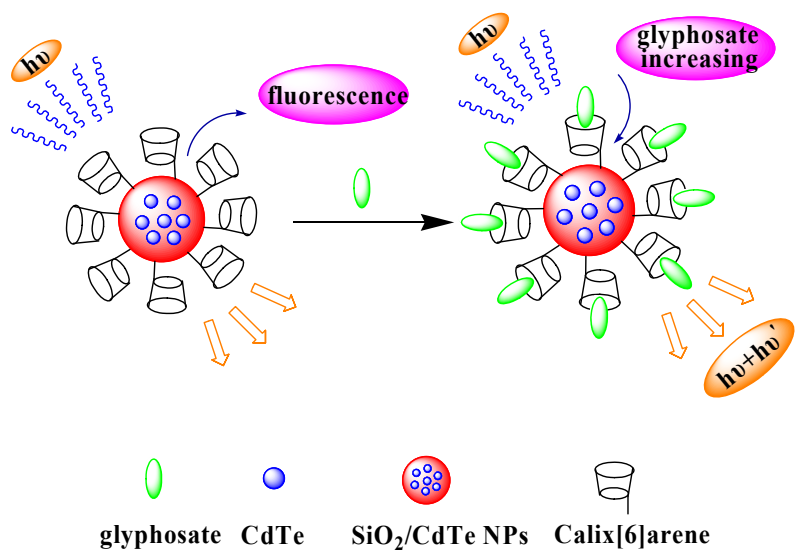

Scheme 2. Formation of Calix[6]arene coated with $\mathrm{SiO}_{2} /$ CdTe NPs detection of glyphosate.

the possibility; we propose recently that the cluster emission is enhanced when the free motion (rotation) of the surface substituents is suppressed [28]. The process of its formation can be found from Scheme 2. However, when the concentration of glyphosate reaches $100 \mathrm{nmol} / \mathrm{L}$, the fluorescence intensity is decreased, which may be caused by the formation of the network structure and induced aggregation [29].

\subsection{Sample Determinations}

In order to check the validity of the proposed method, the standard addition method is applied by adding glyphosate to the previously analyzed solution. The recovery of each pesticide is calculated by comparing the concentration obtained from the spiked mixture with those of the pure pesticides. Table 2 shows the results of analysis of synthetic samples by the standard addition method.

\section{Conclusion}

In this work, we have developed a novel fluorescence 
Table 2. The results of determination of the samples.

\begin{tabular}{cccccc}
\hline Number & Pesticide Sample & Glyphosate added (nmol/L) & Glyphosate found (nmol/L) & R.S.D. (\%) & Recovery (\%) \\
\hline 1 & 1.0 & 4.0 & 4.87 & 3.0 & 97.4 \\
2 & 2.0 & 3.5 & 5.52 & 1.5 & 100.4 \\
3 & 3.0 & 3.0 & 5.78 & 2.6 & 96.3 \\
4 & 4.0 & 2.5 & 6.38 & 1.3 & 98.2 \\
5 & 5.0 & 2.0 & 7.12 & 2.2 & 101.7 \\
\hline
\end{tabular}

probes can be used for ultrasensitive, highly selective, simple, convenient and rapidly efficient detection of glyphosate. The detection limit is low to $0.0725 \mathrm{nmol} \cdot \mathrm{L}^{-1}$, which is the lowest ever report for the other method detection of glyphosate to the best of our knowledge. Furthermore, this work demonstrates $\mathrm{C}[6] / \mathrm{SiO}_{2} / \mathrm{CdTe} \mathrm{NPs}$ have synergetic properties from both QDs and calixarene. Undoubtedly, the results provide very interesting and useful information for the future environmental monitoring analysis, which always have been neglected.

\section{Acknowledgements}

This work was supported by Natural Science Foundation of China (20875002).

\section{REFERENCES}

[1] H. U. Lee, H. Y. Shin, J. Y. Lee, Y. S. Song, G. H. Park and S. W. Kim, "Quantitative Detection of Glyphosate by Simultaneous Analysis of UV Spectroscopy and Fluorescence Using DNA-Labeled Gdd Nanoparticles,” Journal of Agricultural and Food Chemistry, Vol. 58, No. 23, 2010, pp. 12096-12100. doi:10.1021/jf102784t

[2] M. Ibanez, O. J. Pozo, J. V. Sancho, F. J. Lopez and Z. F. Hernande, "Re-Evaluation of Glyphosate Determination in Water by Liquid Chromatography Coupled to Electrospray Tandem Mass Spectrometry," Journal of Chromatography A, Vol. 1134, No. 1-2, 2006, pp. 51-55. doi:10.1016/j.chroma.2006.07.093

[3] P. J. Rice, E. L. Arthur and A. C. Barefoot, "Advances in Pesticide Environmental Fate and Exposure Assessments,” Journal of Agricultural and Food Chemistry, Vol. 55, No. 14, 2007, pp. 5367-5376. doi:10.1021/jf063764s

[4] Y. Ito, T. Goto, S. Yamada, T. Ohno, H. Matsumoto, H. Oka and Y. Ito, "Rapid Determination of Carbamate Pesticidesb in Food Using Dual Counter-Current Chromatography Directly Interfaced with Mass Spectrometry," Journal of Chromatography A, Vol. 1187, No. 1-2, 2008, pp. 53-57. doi:10.1016/j.chroma.2008.01.078

[5] G. Sagratini, J. Manes, D. Giardina, P. Damiani and Y. Pico, "Analysis of Carbamate and Phenylurea Pesticide Residues in Fruit Juices by Soild-Phase Microextraction and Liquid Chromatography-Mass Spectrometry," Journal of Chromatography A, Vol. 1147, No. 2, 2007, pp. 135-143. doi:10.1016/j.chroma.2007.02.066

[6] J. S. Ridlen, G. J. Klopf and T. A. Nieman, "Determina- tion of Glyphosate and Related Compounds Using HPLC with Tris(2,2'-bipyridyl)ruthenium(II) Electrogenerated Chemiluminescence Detection,” Analytica Chimica Acta, Vol. 341, No. 1, 1997, pp. 195-204. doi:10.1016/S0003-2670(96)00493-X

[7] F. S. Bayo, R. V. Hyne and K. L. Desseille, “An Amperometric Method for the Detection of Amitrole, Glyphosate and Its Aminomethyl-Phosphonic Acid Metabolite in Environmental Waters Using Passive Samples," Analytica Chimica Acta, Vol. 675, No. 2, 2010, pp. 125131. doi:10.1016/j.aca.2010.07.013

[8] C. P. Han and H. B. Li, "Host-Molecule-Coated Quantum Dots as Fluorescent Sensors," Analytical and Bioanalytical Chemistry, Vol. 397, No. 4, 2010, pp. 1437-1444. doi:10.1007/s00216-009-3361-0

[9] S. C. Zhang, J. Chen and X. G. Li, "Preparation of Uniform CdSe/Polyelectrolyte Multilayers on the Surface of $\mathrm{SiO}_{2}$ Spheres,” Nanotechnology, Vol. 15, No. 5, 2004, pp. 477-479. doi:10.1088/0957-4484/15/5/012

[10] H. B. Li, Y. Zhang, X. Q. Wang, D. J. Xiong and Y. Q. Bai, "Calixarene Capped Quantum Dots as Luminescent Probes for $\mathrm{Hg}^{2+}$ Ions,” Materials Letters, Vol. 61, No. 7, 2007, pp. 1474-1477. doi:10.1016/j.matlet.2006.07.064

[11] L. D. Chem, J. Liu, X. F. Yu, M. He, X. F. Pei, Z. Y. Tang, Q. Q. Wang, D. W. Pang and Y. Li, "The Biocompatibility of Quantum Dots Probes Used for the Targeted Imaging of Hepatocellular Carcinoma Metastasis,” Biomaterials, Vol. 29, No. 31, 2008, pp. 4170-4176. doi:10.1016/j.biomaterials.2008.07.025

[12] C. Y. Chen, C. T. Cheng, C. W. Lai, K. C. Wu, P. T. Chou, Y. H. Choub and H. T. Chiu, "Potassiumion Recognition by 15-Crown-5 Functionalized CdSe/ZnS Quantum Dots in $\mathrm{H}_{2} \mathrm{O}$," Chemical Communications, Vol. 3, No. 3, 2006, pp. 263-265. doi:10.1039/b512677k

[13] K. Palaniappan, S. A. Hackney and J. Liu, "Supramolecular Control of Complexation-Induced Fluorescence Change of Water-Soluble, Cyclodextrin-Modified CdS Quantum Dots," Chemical Communications, Vol. 23, No. 23, 2004, pp. 2704-2705. doi:10.1039/b409075f

[14] H. B. Li, W. Xiong, Y. Yan, J. A. Liu, H. B. Xu and X. L. Yang, "Selenium Calixarene for Luminescent and Stable Quantum Dots,” Materials Letters, Vol. 60, No. 5, 2006, pp. 703-705. doi:10.1016/j.matlet.2005.09.067

[15] F. Garcia-San Tamaria, V. Salgueirino-Maceira, C. Lopez and L. M. Liz-Marzan, "Synthetic Opals Based on SilicaCoated Gold Nanoparticles,” Langmuir, Vol. 18, No. 11, 2002, pp. 4519-4522. doi:10.1021/la025594t

[16] Y. H. Yang and M. Y. Gao, "Dreparation of Fluorescent 
$\mathrm{SiO}_{2}$ Particles with Single CdTe Nanocrystal Cores by the Reverse Microemulsion Method," Advanced Materials, Vol. 17, 2005, pp. 2354-2357. doi:10.1002/adma.200500403

[17] T. Li, Y. Y. Zhou, J. Y. Sun, D. B. Tang, S. X. Guo and X. P. Ding, "Ultrasensitive Detection of Mercury( II ) Ion Using CdTe Quantum Dots in Sol-Gel-Derived Silica Spheres Coated with Calix[6]arene as Fluorescent Probes," Microchimica Acta, Vol. 175, No. 1-2, 2011, pp. 113-119. doi:10.1007/s00604-011-0655-7

[18] A. Royer, S. Beguin, J. C. Tabet, S. Hulot, M. A. Reding and P. Y. Communal, "Determination of Glyphosate and Aminomethyl Phosphonic Acid Residues in Water by Gas Chromatography with Tandem Mass Spectrometry after Exchange Ion Resin Purification and Derivatisation Application on Vegetable Matrices," Analytical Chemistry, Vol. 72, No. 16, 2000, pp. 3826-3832. doi:10.1021/ac000041d

[19] F. B. C. Coutinho and F. M. L. Coutinho, "Direct Determination of Glyphosate Using Hydrophilic Interaction Chromatography with Coulometric Detection at Copper Microelectrode,” Analytica Chimica Acta, Vol. 592, No. 1, 2007, pp. 30-35. doi:10.1016/j.aca.2007.04.003

[20] Z. L. Chen, W. X. He, M. Beer, M. Megharaj and R. Naidu, "Speciation of Glyphosate, Phosphate and Aminomethylphosphonic Acid in Soil Extracts by Ion Chromatography with Inductively Coupled Plasma Mass Spectrometry,” Talanta, Vol. 78, No. 3, 2009, pp. 852-856. doi:10.1016/j.talanta.2008.12.052

[21] A. Khenifi, Z. Derriche, C. Forano, V. Prevot and C. Mousty, "Glyphosate and Glufosinate Detection at Electrogenerated NiAl-LDH Films," Analytica Chimica Acta, Vol. 654, No.2, 2009, pp. 97-102. doi:10.1016/j.aca.2009.09.023

[22] A. M. Rojano-Delgado, F. Priego-Capote, M. D. Luquede Castvo and R. De Drado, "Screening and Confirmatory Analysis of Glyoxylate: A Biomarker of Plants Resistance against Herbicids,” Talanta, Vol. 82, No. 5, 2010, pp. 1757-1762. doi:10.1016/j.talanta.2010.07.068

[23] M. Kim, J. Stripeikis, F. Inon and M. Tudino, “A Simplified Approach to the Determination of N-Nitroso Glyphosate in Technical Glyphosate Using HPLC with PostDerivatization and Colorimetric Detection,” Talanta, Vol. 72, No. 3, 2007, pp. 1054-1058.

[24] X. Z. Meng, Z. Y. Pan, J. J. Wu, Y. L. Qiu, L. Chen and G. M. Li, "Occurrence of Polybrominated Diphenyl Ethers in Soil from the Central Loess Plateau, China: Role of Regional Range Atmospheric Transport,” International Toxicology of Mixtures Conference, Vol. 83, No. 10, 2011, pp. 1391-1397. doi:10.1016/j.talanta.2006.12.047

[25] J. C. Young, K. S. Khan and B. P. Marriage, "Fluorescence Detection and Determination of Glyphosate via Its N-Nitroso Derivative by Thin-Layer Chromatography," Journal of Agricultural and Food Chemistry, Vol. 25, No. 4, 1977, pp. 918-922. doi:10.1021/jf60212a069

[26] H. Li and F. Qu, "Synthesis of CdTe Quantum Dots in Sol-Gel-Derived Composite Silica Spheres Coated with Calix[4]arene as Luminescent Probes for Pesticides," Materials Letters, Vol. 19, 2007, pp. 4148-4154.

[27] D. Sun, G. G. Luo, N. Zhang, Q. J. Xu and Y. C. Jin, “A Lamella 2D Siliver(I) Coordination Polymer Constructed from in Situ Generated 2-Mercaptobenzoic Acid," Inorganic Chemistry Communications, Vol. 13, No. 2, 2010, pp. 306-309. doi:10.1016/j.inoche.2009.12.011

[28] T. Hiratani and K. Konishi, "Surface-Cap-Mediated HostGuest Chemistry of Semiconductor CdS: Intercalative Cation Accumulation around a Phenyl-Capped CdS Cluster and its Notable Effects on the Cluster Photoluminescence,” Angewandte Chenie International Edition, Vol. 43, No. 44, 2004, pp. 5943-5946.

[29] Y. F. Chen and Z. Rosenzweig, "Luminescent CdS Quantum Dots as Selective Ion Probes," Analytical Chemistry, Vol. 74, No. 19, 2002, pp. 5132-5138.

doi:10.1021/ac0258251 